\title{
Utility of rapid antibody tests to exclude HIV-1 infection among infants and children aged $<18$ months in a low-resource setting
}

\author{
Ann M. Buchanan a,b,c,*, Behzad Nadjm ${ }^{\mathrm{d}}$, Ben Amos ${ }^{\mathrm{e}}$, George Mtove ${ }^{\mathrm{f}}$, David Sifuna ${ }^{\mathrm{b}}$, \\ Coleen K. Cunningham ${ }^{a}$, John A. Crump ${ }^{b, c, g, h}$, Hugh Reyburn $^{\mathrm{d}}$ \\ a Division of Infectious Diseases, Department of Pediatrics, Duke University Medical Center, Durham, NC, USA \\ ${ }^{\mathrm{b}}$ Kilimanjaro Christian Medical Centre, Moshi, Tanzania \\ ${ }^{\mathrm{c}}$ Duke Global Health Institute, Duke University, Durham, NC, USA \\ d London School of Hygiene and Tropical Medicine, London, UK \\ e Teule Hospital, Muheza, Tanga, Tanzania \\ ${ }^{\mathrm{f}}$ National Institute for Medical Research, Amani Centre, Tanga, Tanzania \\ ${ }^{g}$ Division of Infectious Diseases and International Health, Department of Medicine, Duke University Medical Center, Durham, NC, USA \\ ${ }^{\mathrm{h}}$ Kilimanjaro Christian Medical College, Tumaini University, Moshi, Tanzania
}

\section{A R T I C L E I N F O}

\section{Article history:}

Received 14 April 2012

Received in revised form 20 June 2012

Accepted 1 August 2012

\section{Keywords:}

Human immunodeficiency virus

Rapid antibody test

Infants

Children

Early diagnosis

\begin{abstract}
A B S T R A C T
Background: Excluding HIV infection among infants and young children in resource-poor settings where nucleic acid amplification tests (NAAT) are not routinely available remains a considerable challenge. Objectives: To assess the performance of two rapid HIV antibody tests (RT) used alone and in parallel for excluding HIV infection among acutely ill infants and children $<18$ months in comparison to NAAT in a region where maternal HIV prevalence was approximately $7 \%$.

Study Design: Infants and children $\geq 2<18$ months admitted to hospital with an acute febrile illness had two rapid antibody tests in parallel, with single and parallel results subsequently compared against NAAT. Results: HIV prevalence among 1602 enrolled infants was 3.4\%. All 1526 infants with 2 negative RT were HIV negative by NAAT. All 46 infants with 2 positive RT were HIV positive by NAAT. The overall specificity of two rapid tests for excluding HIV infection was $99.5 \%$. Sensitivity and specificity were $\geq 99 \%$ and $>98 \%$, respectively, across all age brackets $\geq 2<18$ months. Overall sensitivity and specificity for a single RT was $98.2 \%$ and $99 \%$, respectively, for Determine, and $85.5 \%$ and $99.6 \%$, respectively, for Capillus.

Conclusions: In a setting with a maternal HIV prevalence rate of $<10 \%$, a single negative RT had excellent specificity and two negative RT performed in parallel had a perfect negative predictive value for HIV infection among acutely ill patients $<18$ months of age. In this and similar settings, RT could assist with excluding HIV infection with much lower complexity and cost than NAAT.
\end{abstract}

(C) 2012 Elsevier B.V. All rights reserved.

\section{Background}

The ability to diagnose or exclude HIV infection in infants and young children is critical for both patient management and aversion of mortality. The diagnosis of HIV in infants and young children has conventionally relied on the use of nucleic acid amplification tests (NAAT). However, NAAT is still not widely available in lowresource countries. When NAAT is available, it is unlikely to provide results rapidly enough to influence acute care decisions. HIV rapid antibody tests (RT) could provide a solution for timely infant and young child diagnosis in areas without NAAT and for areas with prolonged NAAT turnaround times.

\footnotetext{
* Corresponding author at: KCMC-Duke Collaboration, Box 3010, Kilimanjaro Christian Medical Centre, Moshi, Tanzania. Tel.: +255 787 955649; fax: +255027 2754381 .

E-mail address: ann.buchanan@duke.edu (A.M. Buchanan).
}

The presence of maternal HIV antibody in HIV-exposed, uninfected infants may produce false-positive results, though the majority will serorevert prior to 15 months of age. ${ }^{1-4}$ The sensitivity of RT may also be influenced by seronegativity during the conversion illness associated with HIV and thus may fail to detect early acute HIV infection. ${ }^{5}$ The performance of a single RT compared to parallel RT has not been well described under the age of 18 months. Presently, the World Health Organization recommends RT from as early as nine months to exclude infection in non-breastfeeding infants. ${ }^{6}$ In practice, many providers in subSaharan Africa remain reluctant to use RT for children $<18$ months of age.

\section{Objectives}

The aim of this study was to evaluate the performance of two HIV-1/2 RT performed alone and in parallel to exclude HIV 
infection among children aged $<18$ months, who presented to a rural district hospital in Tanzania with an acute febrile illness. The clinical presentation of infected infants and young children is also described.

\section{Study design}

\subsection{Study design and subjects}

The sample subset for the present study was taken from a larger observational study aimed at measuring invasive bacterial disease in an area with intense malaria transmission. The study was conducted in Teule Hospital, Muheza, Tanga Region, in northeast Tanzania, from June 2006 to May 2007. This district hospital serves a rural population of approximately 277,000 people. HIV seroprevalence among pregnant women in Muheza District in 2007 was $7.2 \%{ }^{7}$ Children ages $>2$ months to $\leq 13$ years with a current fever or history of fever $48 \mathrm{~h}$ prior to admission were eligible for enrollment into the study. Full details are described elsewhere. ${ }^{8}$ For the present study, we tested all available archived specimens on infants/children $<18$ months of age who had been tested for HIV-1 by rapid test in parallel, but without a confirmatory NAAT $(n=1546)$.

\subsection{Laboratory procedures}

As part of the initial study, infants and children had two rapid HIV-1/2 serum antibody tests performed at the time of study entry: Capillus (Trinity Biotech, County Wicklow, Ireland) and Determine (Abbott Laboratories, Abbott Park, IL, USA). ${ }^{9}$ RT were performed at the bedside by nurses, trained and supervised by the study senior medical team. Medical history, physical examination, and a blood culture were also obtained. ${ }^{8}$ Children under the age of 18 months with two positive RT had CD4+ T-lymphocyte count and percentage along with serum or plasma HIV-1 RNA measured by NAAT (Abbott Real-Time m2000 System, Abbott Molecular, Illinois, USA). ${ }^{10,11}$ Children with discordant RT had HIV-1 enzyme linked immunosorbent assay (ELISA) (Vironistika Uniform II Plus-O Test, bio-Mérieux, NC, USA), but no further testing if negative on ELISA. Children under the age of 18 months with two negative RT also had no further testing at the time of the initial study. The present study tested samples without prior NAAT from the original 2006 to 2007 study that had been in storage at $-80^{\circ} \mathrm{C}$ for $4-5$ years, which included all infants/children $<18$ months with concordant negative RT or discordant RT with negative ELISA. These samples ( $n=1546$ ) were tested with HIV-1 RNA PCR by a pooled method, using 10 samples per well and 24-96 wells per run. Two positive and one negative control were used for each run. The assay platform participated successfully in the US National Institutes of Health Viral Quality Assessment program (VQA, Rush-Presbyterian-St. Luke's Medical Center, Chicago, IL, USA). If HIV-1 RNA was detected in a pool, all contributing samples were re-tested individually. HIV1 RNA PCR testing was also repeated on a subset of the originally positive samples to confirm positivity after $4-5$ years in storage. Finally, HIV antibody testing was repeated for samples with initially discordant RT results and undetectable HIV-1 RNA PCR. In March 2008, after the main study and before the present study, the Tanzania Ministry of Health HIV testing guidelines required replacement of the Capillus HIV-1/HIV-2 with the SD Bioline HIV$1 /$ HIV-2 test (Standard Diagnostics Inc, South Korea). Consequently repeat rapid antibody testing on stored samples was done with the Determine and SD Bioline rapid diagnostic tests. HIV-infected was defined as a single positive HIV-1 RNA PCR $>400$ copies/ml; HIV uninfected was defined as a single negative undetectable HIV-1 RNA PCR.
Table 1

HIV rapid test (RT) results among children $<18$ months using Determine and Capillus RT, by age group, Teule Hospital, Tanzania.

\begin{tabular}{lcc}
\hline & NAAT positive & NAAT negative \\
\hline$\geq 2<6$ months & & 0 \\
RT concordant positive & 6 & 2 \\
RT discordant & 0 & 229 \\
RT concordant neg & 17 & 0 \\
$\geq 6<9$ months & 0 & 8 \\
RT concordant positive & 0 & 331 \\
RT discordant & 7 & \\
RT concordant negative & 3 & 5 \\
$\geq 9<12$ months & 0 & 362 \\
RT concordant positive & & \\
RT discordant & 16 & 0 \\
RT concordant negative & 2 & 604 \\
$\geq 12<18$ months & 0 & \\
RT concordant positive & & \\
RT discordant & & \\
RT concordant negative & & \\
\hline
\end{tabular}

\subsection{Data analysis}

Data were first scanned into a Microsoft Access database using the Cardiff Teleform system (Cardiff, Vista, California, USA), and then initially analyzed in Stata 10.0 (StataCorp LP, College Station, TX, USA). The present analysis was done using Stata 11.0. Sensitivity and specificity of a single RT, concordant negative RT, discordant RT, and concordant positive RT was determined and compared against HIV-1 RNA PCR results. The test of medians was used to compare median HIV-1 RNA levels.

\subsection{Research ethics}

The study was approved by ethics committees of the Tanzania National Institute for Medical Research and the London School of Hygiene and Tropical Medicine, UK.

\section{Results}

A total of 1602 samples from children aged $<18$ months who had previously undergone RT with both Capillus and Determine were available. Results were grouped into the following age categories: $\geq 2<6$ months $(n=241) ; \geq 6<9$ months $(n=356) ; \geq 9<12$ months $(n=377) ; \geq 12<18$ months $(n=628)$. Of the 1602 samples, 1526 (95.3\%) had concordant negative RT results, and 46 (2.9\%) had concordant positive RT results (Fig. 1). The 1526 concordant negative specimens were all negative on testing by NAAT (HIV-1 RNA PCR) performed after $4-5$ years in storage. The 20 specimens with discordant RT and negative ELISA were also all NAAT-negative when tested for the present study. The 46 specimens with concordant positive RT were positive on NAAT confirmatory testing performed during the original study period. Twelve of the samples that were originally NAAT positive were retested in 2011, and all were still positive on retest.

There were 30 RT discordant samples, of which 9 (30\%) were NAAT-positive and 21 (70\%) were NAAT-negative. Of these 30 , $23(76.7 \%)$ were Determine positive and Capillus negative, and 7 (23.3\%) were Determine negative and Capillus positive (Fig. 1). Among infants $\geq 2<6$ months, 6 had discordant results, 4 of whom were NAAT-positive. There were 8 discordant results among infants $\geq 6<9$ months, all of which were negative by NAAT. For infants $\geq 9<12$ months, there were also 8 discordant results, with 3 NAATpositive. Finally, for children $\geq 12<18$ months, there were also 8 discordant results, with only 2 NAAT-positive (Table 1 ). On repeat RT of the 21 samples with discordant RT and negative NAAT, 7 (33.3\%) were discordant using SD Bioline and Determine (Table 2). Thus, of 1547 patients aged < 18 months with negative NAAT, 7 


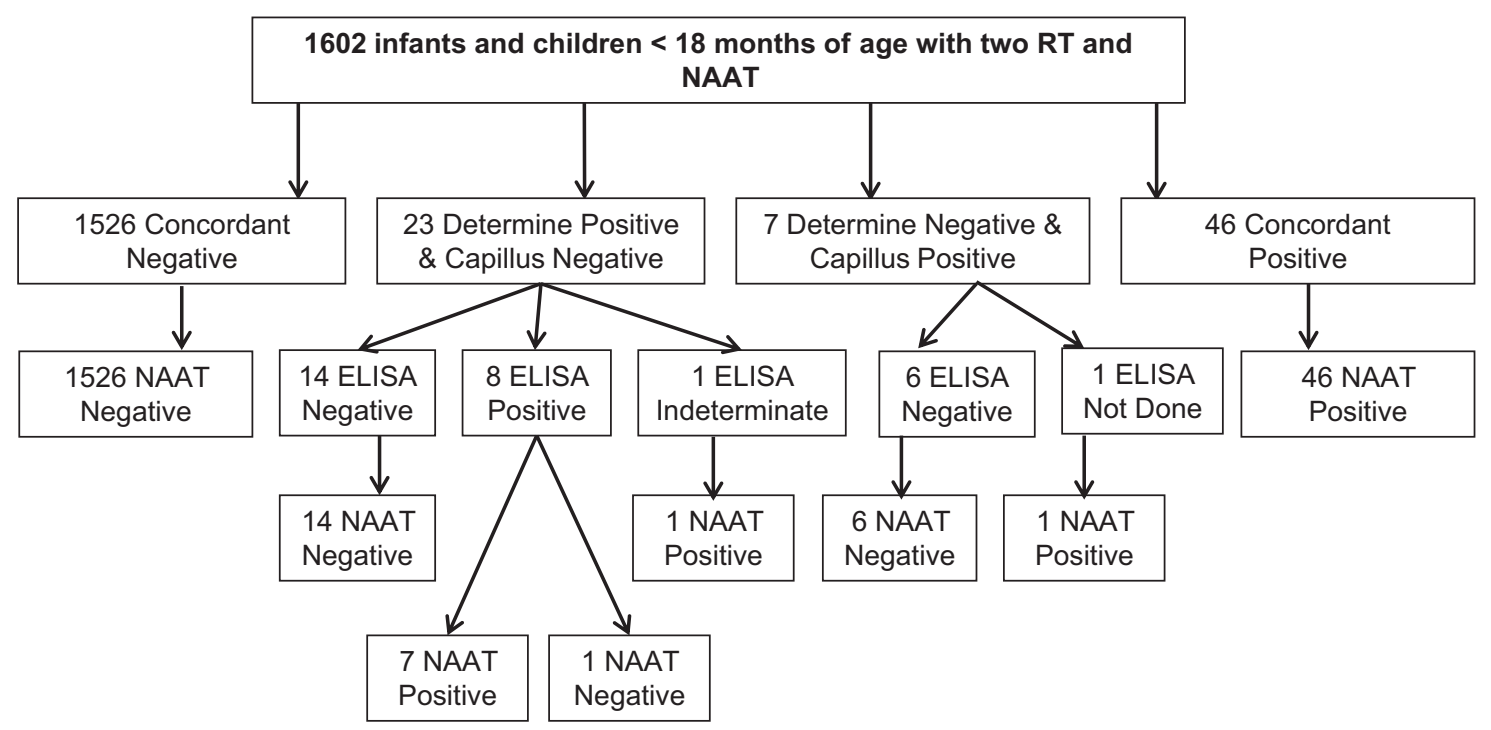

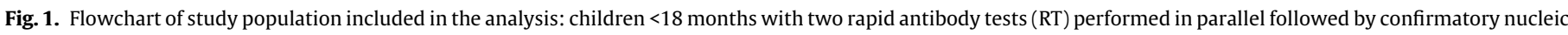
acid amplification test (NAAT).

\section{Table 2}

HIV Rapid test (RT) results among children $<18$ months after repeat RT with SD Bioline on discordant negative samples $(n=21)$, by age group, Teule Hospital, Tanzania.

\begin{tabular}{lcc}
\hline & NAAT positive & NAAT negative \\
\hline$\geq 2<6$ months & 6 & 0 \\
RT concordant positive & 4 & 0 \\
RT discordant & 0 & 231 \\
RT concordant neg & 17 & 0 \\
$\geq 6<9$ months & 0 & 4 \\
RT concordant positive & 0 & 335 \\
RT discordant & 7 & \\
RT concordant negative & 3 & 2 \\
$\geq 9<12$ months & 0 & 365 \\
RT concordant positive & & \\
RT discordant & 16 & 0 \\
RT concordant negative & 2 & 609 \\
$12<18$ months & 0 & \\
RT concordant positive & & \\
RT discordant & & \\
RT concordant negative & & \\
\hline
\end{tabular}

(0.5\%) had discordant RT (Table 2). Following repeat testing, discordant RT among infants/young children with negative NAAT decreased with increasing age group from 6 months onward (Fig. 2).

The negative predictive value (95\% confidence intervals) for excluding HIV-infection using two RT in parallel was $100 \%$ (99.7-100\%) for all patients $\geq 2<18$ months. The positive predictive value of one or more positive RT for correctly detecting HIV infection was $88.7 \%$ (78.5-94.4\%) for all patients $\geq 2<18$ months. Specificity by age bracket ranged from 98.8 to $100 \%$, and sensitivity,

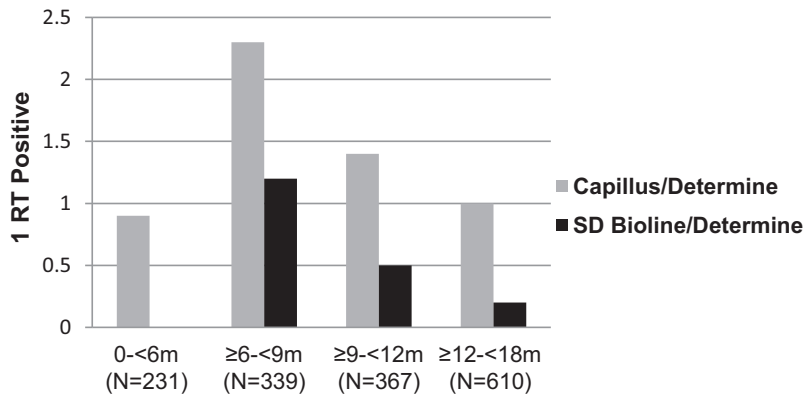

Fig. 2. Percentage of uninfected children with discordant rapid test (RT) by age, test. from 99 to $100 \%$ (Table 3). Sensitivity and specificity for a single RT was 98.2\% (90.4-99.7\%) and 99\% (98.4-99.4\%), respectively, for Determine, and 85.5\% (73.8-92.4\%) and 99.6\% (99.2-99.8\%), respectively, for Capillus (Table 4 ).

Finally, there was a range of clinical presentations and laboratory values among the 55 infants/children with a positive NAAT in the study cohort (Table 5). The median (range) HIV1 RNA level was 399,995 $(684,14,674,839)$ copies/mL. Eight $(14.5 \%)$ had HIV-1 RNA levels $>5 \times 10^{6}$ copies/mL. The median HIV1 RNA level for those with concordant positive RT was 348,818 $(684,14,674,839)$ copies/mL, compared to $1,391,712(15,495$, $3,354,803$ ) copies/mL for those with discordant RT, though this difference was not statistically significant $(p=0.253)$. Median (range) CD4+ T-lymphocyte absolute count for the 25 who had results was $618(44,3616)$ cells $/ \mathrm{mm}^{3}$, and median (range) CD4+ T-lymphocyte percentage was $14(3-30)$. Nine (16.4\%) of the 55 were diagnosed with a bloodstream infection during their hospitalization. Thirty (54.5\%) had a diagnosis of very severe or severe pneumonia as defined by the WHO. ${ }^{12}$ Twelve (22\%) died during hospitalization, 7 (58\%) of whom died within $48 \mathrm{~h}$ of admission.

\section{Discussion}

In a cohort of pediatric patients $<18$ months presenting to hospital with an acute febrile illness in Tanzania, a country with a generalized HIV epidemic, two negative RT performed in parallel had a negative predictive value for HIV infection of $100 \%$, and a single negative RT had a negative predictive value of $99.9 \%$ (Determine) and 99.5\% (Capillus). No infected infant had two negative RT; no uninfected infant had two positive RT; and discordant RT results occurred in $<2 \%$ of those tested. Our analysis demonstrates the utility of RT for excluding HIV infection in the acutely ill infant or young child in this low-resource setting where rapid turnaround NAAT is unavailable.

We have assumed absence of knowledge regarding the HIV status of the mother as this was not documented in the study and in routine care, its presence or reliability cannot be assumed at the time of admission of a child with a febrile illness. However, it is a conservative assumption since the information on maternal status is now often available from testing in the antenatal or intrapartum period, and in addition, certain illnesses such as pneumonia or malnutrition increase the probability of HIV infection in 
Table 3

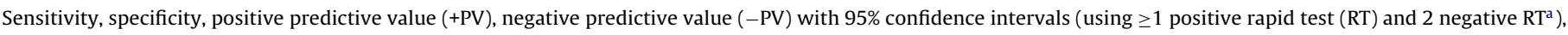
Teule Hospital, Tanzania.

\begin{tabular}{|c|c|c|c|c|}
\hline & Sensitivity (\%) & Specificity (\%) & $+\mathrm{PV}(\%)$ & $-\mathrm{PV}(\%)$ \\
\hline All, $\geq 2<18$ months & $100[0.931-1]$ & 99.5 [0.991-0.998] & $88.7[0.785-0.944]$ & $100[0.997-1]$ \\
\hline$\geq 2<6$ months & $99[0.71-1]$ & $100[0.983-1]$ & $99[0.71-1]$ & $100[0.983-1]$ \\
\hline$\geq 6<9$ months & $99.4[0.807-1]$ & $98.8[0.97-0.995]$ & $81[0.6-0.923]$ & $100[0.988-1]$ \\
\hline$\geq 9<12$ months & $99[0.71-1]$ & 99.5 [0.98-0.999] & 83.3 [0.552-0.953] & $100[0.989-1]$ \\
\hline$\geq 12<18$ months & $99.4[0.816-1]$ & $99.8[0.991-1]$ & $94.7[0.754-0.991]$ & $100[0.993-1]$ \\
\hline
\end{tabular}

a 21 discordant samples with negative NAAT retested with SD Bioline/Determine; all others, Capillus/Determine.

infants. While our estimate of sensitivity and specificity are unaffected by pre-test probability, our estimates of positive predictive value or negative predictive value are likely to be unrealistically low and high, respectively, if the mother is known to be HIVpositive.

Our results are relevant to a number of different scenarios. First, for any high risk infant - whether born to an HIV-infected mother or with signs and symptoms suggestive of immunosuppression a single test is obviously insufficient. Two RT with complementary qualities - either highly specific or sensitive - is recommended. For infected infants and children $<18$ months in our study, we had no concordant negative RT results, and among those with two negative RT, not a single patient was HIV-infected. Discordant tests require NAAT, but in the acute care setting we are looking for reassurance for the mother and provider, or, confirmation of infection. In either scenario, a correct diagnostic test will avert illness and relieve anxiety.

A single negative test in a low risk infant, which also includes a setting of low population prevalence, is highly predictive for excluding HIV infection and is an acceptable screening option. Finally, a single positive test, even one with no suspicion of HIV infection or very low risk, should have a second test with a different RT. Close follow-up and NAAT will be needed in time.

While HIV NAAT is the preferred diagnostic method for infants and children aged $<18$ months, its use is still not widespread. It is estimated that only $8 \%$ of HIV-exposed infants in resource-poor settings had access to a virological testing method in 2008. ${ }^{13,14}$ Even when available, turnaround times for NAAT may average 4 weeks or more, meaning the value of NAAT for acute care decisionmaking is low. An acutely ill child with two negative or even a single negative RT would allow clinicians to focus on diseases other than HIV; alternatively, a positive RT could inform the differential diagnosis to include conditions typically associated with immune suppression. The majority of HIV-infected children will die before their second birthday without access to antiretroviral therapy, ${ }^{13}$ and in this study most children that died with HIV did so within $48 \mathrm{~h}$ of admission, making timely identification of the HIV-infected infant or young child critical. HIV antibody testing using RT is simpler to perform, faster, and much cheaper than NAAT. ${ }^{15}$

There are important differences in RT with respect to sensitivity for early diagnosis of acute HIV infection in adults. ${ }^{16-18}$ Differences in the performance of RT among infants have also been described. ${ }^{19,20}$ In our study, there were nine infected infants/children with discordant RT, and all but one was Capillus negative/Determine positive. False negative Capillus results among infected infants have been reported elsewhere, and have been shown to be associated with low HIV-1 viral load and concurrent antiretroviral therapy. ${ }^{20}$ Furthermore, the Capillus assay is difficult to perform, using three different reagents and six different steps in the process which typically require a high level of laboratory skill. ${ }^{16}$ The Capillus assay is no longer part of Tanzania's national algorithm for HIV testing. ${ }^{21}$ The Determine assay has been shown to be a more sensitive assay compared to other RT for the detection of HIV exposure and seroreversion during infancy. ${ }^{19}$

The higher median HIV-1 RNA PCR levels among infected infants with discordant RT in our study compared to those infected with concordant RT is interesting. Whether this represents discordance due to acute HIV infection cannot be determined. Acute HIV infection, while well-described in adults, $5,22,23$ is less well-described among infants and young children. Adults with acute HIV infection have a burst of plasma viremia typically in the first several weeks after infection. ${ }^{5,24}$ In contrast to adults, vertically infected infants maintain high levels of virus (typically $>10^{5}$ HIV-1 RNA copies $/ \mathrm{mL}$ ) for several months while typically preserving a normal CD4+ lymphocyte percentage for age. ${ }^{24-26}$. A child with acute HIV infection may have a false negative antibody test because the child has not yet mounted an antibody response to the virus ${ }^{27}$; or, a child's primary production of antibody may be suppressed by the presence of maternal IgG antibody. ${ }^{28}$ Given that the majority of infants in our study were breastfed, acute postnatally acquired HIV infection may explain some of the discordant results among infected infants.

Our study was limited by the fact that samples were in storage for up to five years before performing the majority of the NAAT testing, which could affect assay sensitivity. However, 12 previously NAAT-positive samples were retested after $4-5$ years in storage and all were still positive. Furthermore, no test required repeating to show concordance. Another limitation is the relatively low prevalence of HIV infection in our population of $3.4 \%$. Thus, while sensitivity was high across all age groups, confidence intervals are wide and positive predictive value is clearly affected by the low prevalence. We also did not include infants less than 2 months of age in the study and thus our results cannot be applied to this age group. Furthermore, we did not collect information regarding maternal or infant use of highly active antiretroviral therapy (HAART), though

Table 4

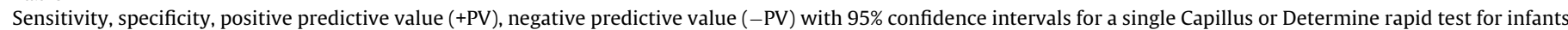
and children $\geq 2<18$ months of age, Teule Hospital, Tanzania.

\begin{tabular}{|c|c|c|c|c|}
\hline & Sensitivity (\%) & Specificity (\%) & +PV (\%) & -PV (\%) \\
\hline Capillus & $85.5[0.738-0.924]$ & 99.6 [0.992-0.998] & $88.7[0.774-0.947]$ & 99.5 [0.99-0.997] \\
\hline Determine & $98.2[0.904-0.997]$ & 99 [0.984-0.994] & $78.3[0.672-0.864]$ & $99.9[0.996-1]$ \\
\hline
\end{tabular}


Table 5

Select demographic characteristics of HIV-infected infants and children $\geq 2<18$ months of age, Teule Hospital, Tanzania.

\begin{tabular}{|c|c|c|c|c|c|c|c|}
\hline Age Group (months) & Parallel $\mathrm{RT}^{\mathrm{a}}$ & ELISA & HIV-1 RNA PCR & Confirmatory HIV-1 RNA PCR ${ }^{b}$ & $\mathrm{CD} 4$ & $\mathrm{CD} 4 \%$ & Death \\
\hline $0<6$ & $\mathrm{CP}$ & - & $>10,000,000$ & - & 338 & 13 & $\mathrm{Y}$ \\
\hline $0<6$ & $\mathrm{CP}$ & - & 473,074 & - & 562 & 7 & $\mathrm{~N}$ \\
\hline $0<6$ & $\mathrm{CP}$ & - & $>10,000,000$ & $>10,000,000$ & - & - & $\mathrm{N}$ \\
\hline $0<6$ & $\mathrm{D}$ & Pos & $3,354,803$ & - & - & - & $\mathrm{Y}$ \\
\hline $0<6$ & $\mathrm{D}$ & - & $1,364,430$ & - & - & - & $\mathrm{Y}$ \\
\hline $0<6$ & $\mathrm{D}$ & Pos & $3,296,500$ & - & 182 & 3 & $\mathrm{~N}$ \\
\hline $0<6$ & $\mathrm{CP}$ & - & $5,087,096$ & - & - & - & $\mathrm{N}$ \\
\hline $0<6$ & $\mathrm{CP}$ & - & 36,002 & - & - & - & $\mathrm{N}$ \\
\hline $0<6$ & $\mathrm{D}$ & IND & $1,440,593$ & - & 375 & 14 & $\mathrm{~N}$ \\
\hline $0<6$ & $\mathrm{CP}$ & - & 349,311 & $1,522,687$ & - & - & $\mathrm{N}$ \\
\hline$\geq 6<9$ & $\mathrm{CP}$ & - & $9,937,669$ & - & 470 & 9 & $\mathrm{~N}$ \\
\hline$\geq 6<9$ & $\mathrm{CP}$ & - & 109,350 & - & 597 & 11 & $\mathrm{Y}$ \\
\hline$\geq 6<9$ & $\mathrm{CP}$ & - & 154,867 & - & 357 & 25 & $\mathrm{~N}$ \\
\hline$\geq 6<9$ & $\mathrm{CP}$ & - & 795,686 & - & 702 & 8 & $\mathrm{~N}$ \\
\hline$\geq 6<9$ & $\mathrm{CP}$ & - & 50,988 & 17,043 & - & - & $\mathrm{Y}$ \\
\hline$\geq 6<9$ & $\mathrm{CP}$ & - & 684 & - & - & - & $\mathrm{N}$ \\
\hline$\geq 6<9$ & $\mathrm{CP}$ & - & 633,117 & - & - & - & $\mathrm{N}$ \\
\hline$\geq 6<9$ & $\mathrm{CP}$ & - & 711,240 & 376,795 & - & - & $\mathrm{N}$ \\
\hline$\geq 6<9$ & $\mathrm{CP}$ & - & $14,674,839$ & $8,089,390$ & - & - & $\mathrm{N}$ \\
\hline$\geq 6<9$ & $\mathrm{CP}$ & - & 314,776 & - & - & - & $\mathrm{N}$ \\
\hline$\geq 6<9$ & $\mathrm{CP}$ & - & $>10,000,000$ & $>10,000,000$ & - & - & $\mathrm{Y}$ \\
\hline$\geq 6<9$ & $\mathrm{CP}$ & - & $8,309,771$ & - & 1923 & 12 & $\mathrm{Y}$ \\
\hline$\geq 6<9$ & $\mathrm{CP}$ & - & 348,325 & 143,608 & 526 & 16 & $\mathrm{~N}$ \\
\hline$\geq 6<9$ & $\mathrm{CP}$ & - & 8,102 & - & - & - & $\mathrm{N}$ \\
\hline$\geq 6<9$ & $\mathrm{CP}$ & - & $4,076,489$ & - & - & - & $\mathrm{Y}$ \\
\hline$\geq 6<9$ & $\mathrm{CP}$ & - & 133,548 & - & 217 & - & $\mathrm{N}$ \\
\hline$\geq 6<9$ & $\mathrm{CP}$ & - & 63,360 & - & - & - & $\mathrm{Y}$ \\
\hline$\geq 9<12$ & $\mathrm{D}$ & Pos & 332,346 & - & - & - & $\mathrm{N}$ \\
\hline$\geq 9<12$ & $\mathrm{CP}$ & - & 78,250 & - & 723 & 9 & $\mathrm{Y}$ \\
\hline$\geq 9<12$ & $\mathrm{CP}$ & - & $>10,000,000$ & - & 44 & - & $\mathrm{N}$ \\
\hline$\geq 9<12$ & $\mathrm{D}$ & Pos & 15,495 & 2643 & - & - & $\mathrm{N}$ \\
\hline$\geq 9<12$ & $\mathrm{D}$ & Pos & 56,486 & - & - & - & $\mathrm{N}$ \\
\hline$\geq 9<12$ & $\mathrm{CP}$ & - & 3710 & - & - & - & $\mathrm{N}$ \\
\hline$\geq 9<12$ & $\mathrm{CP}$ & - & $2,064,573$ & - & 577 & 9 & $\mathrm{~N}$ \\
\hline$\geq 9<12$ & $\mathrm{CP}$ & - & 4281 & - & 940 & 18 & $\mathrm{~N}$ \\
\hline$\geq 9<12$ & $\mathrm{CP}$ & - & 146,091 & - & 1129 & 11 & $\mathrm{~N}$ \\
\hline$\geq 9<12$ & $\mathrm{CP}$ & - & 341,303 & - & - & - & $\mathrm{N}$ \\
\hline$\geq 12<18$ & $\mathrm{CP}$ & - & 231,890 & - & 618 & 15 & $\mathrm{~N}$ \\
\hline$\geq 12<18$ & $\mathrm{D}$ & Pos & $2,764,591$ & - & - & - & $\mathrm{N}$ \\
\hline$\geq 12<18$ & $\mathrm{CP}$ & - & 206,501 & - & 1190 & 25 & $\mathrm{~N}$ \\
\hline$\geq 12<18$ & $\mathrm{CP}$ & - & $4,695,058$ & - & 1161 & 30 & $\mathrm{Y}$ \\
\hline$\geq 12<18$ & $\mathrm{D}$ & Pos & $1,391,712$ & - & 352 & 7 & $\mathrm{~N}$ \\
\hline$\geq 12<18$ & $\mathrm{CP}$ & - & $4,505,055$ & - & - & - & $\mathrm{N}$ \\
\hline$\geq 12<18$ & $\mathrm{CP}$ & - & 819,483 & - & 1645 & 16 & $\mathrm{~N}$ \\
\hline$\geq 12<18$ & $\mathrm{CP}$ & - & 213,027 & - & 908 & 17 & $\mathrm{~N}$ \\
\hline$\geq 12<18$ & $\mathrm{CP}$ & - & 325,460 & - & - & - & $\mathrm{N}$ \\
\hline$\geq 12<18$ & $\mathrm{CP}$ & - & 217,347 & 61,415 & - & - & $\mathrm{N}$ \\
\hline$\geq 12<18$ & $\mathrm{CP}$ & - & 61,625 & - & - & - & $\mathrm{N}$ \\
\hline$\geq 12<18$ & $\mathrm{CP}$ & - & 650,468 & 244,639 & - & - & $\mathrm{N}$ \\
\hline$\geq 12<18$ & $\mathrm{CP}$ & - & 135,878 & - & 3616 & 30 & $\mathrm{Y}$ \\
\hline$\geq 12<18$ & $\mathrm{CP}$ & - & 289,509 & - & 940 & 18 & $\mathrm{~N}$ \\
\hline$\geq 12<18$ & $\mathrm{CP}$ & - & 399,995 & 665,402 & - & - & $\mathrm{N}$ \\
\hline$\geq 12<18$ & $\mathrm{CP}$ & - & $4,484,289$ & $3,966,528$ & - & - & $\mathrm{N}$ \\
\hline$\geq 12<18$ & $\mathrm{CP}$ & - & $4,392,507$ & - & 1806 & 28 & $\mathrm{~N}$ \\
\hline$\geq 12<18$ & $\mathrm{CP}$ & - & 602,017 & - & - & - & $\mathrm{N}$ \\
\hline
\end{tabular}

a $\mathrm{CP}$, concordant positive; $\mathrm{D}$, discordant.

given the time period was five years ago, it is unlikely that many infants/children in this age range would have been diagnosed and on HAART. Finally, our study was conducted only in Tanzania, and the results may not be generalizable to other resourcepoor settings, particularly where different HIV-1 subtypes may exist.

In summary, our findings suggest that a single RT may provide highly predictive results on the true HIV status of a low risk infant whose maternal status is unknown and that two RT used in parallel can provide highly predictive results in infants born to HIV positive mothers. While the utility of RT may not be surprising for children > 12 months of age, that RT performed well among younger age groups has important implications. In this and similar settings, RT can be used to reasonably exclude infection in the acutely ill infant or young child until NAAT is widely and rapidly available.

\section{Funding}

Core funding for the study was provided by European Commission (Europaid) grant code SANTE/2004/078-607. Abbott Pharmaceuticals provided reagents for HIV-testing and HIV-1 RNA PCR test kits.

\section{Competing interests}

No conflicts of interest to declare. 


\section{Ethical approval}

The study was approved by ethics committees of the Tanzania National Institute for Medical Research and the London School of Hygiene and Tropical Medicine, UK.

\section{Acknowledgements}

This publication was made possible with help from the Duke University Center for AIDS Research (CFAR), an NIH funded program (5P30 AI064518).

\section{References}

1. Simpson BJ, Andiman WA. Difficulties in assigning human immunodeficiency virus-1 infection and seroreversion status in a cohort of HIV-exposed in children using serologic criteria established by the Centers for Disease Control and Prevention. Pediatrics 1994;93(May (5)):840-2.

2. Chantry CJ, Cooper ER, Pelton SI, Zorilla C, Hillyer GV, Diaz C. Seroreversion in human immunodeficiency virus-exposed but uninfected infants. Pediatr Infect Dis J 1995;14(May (5)):382-7.

3. Moodley D, Bobat RA, Coutsoudis A, Coovadia HM. Predicting perinatal human immunodeficiency virus infection by antibody patterns. Pediatr Infect Dis 1995;14(October (10)):850-2.

4. Gulia J, Kumwenda N, Li Q, Taha TE. HIV seroreversion time in HIV-1-uninfected children born to HIV-1-infected mothers in Malawi. J Acquir Immune Defic Syndr 2007;46(November-(3)):332-7.

5. Fiebig EW, Wright DJ, Rawal BD, Garrett PE, Schumacher RT, Peddada L. Dynamics of HIV viremia and antibody seroconversion in plasma donors: implications for diagnosis and staging of primary HIV infection. AIDS 2003;17(September(13)):1871-9.

6. World Health Organization. Antiretroviral therapy of HIV-infection in infants and children in resource-limited settings: towards universal access: recommendations for a public health approach. Geneva: WHO; 2006.

7. Edmonds S, Shangalawe L, Meadway J. Getting pregnant women on to HAART (highly active antiretroviral therapy): developing a strategy for advanced prevention of mother-to-child transmission of HIV (PMTCT+) in rural Tanzania. HIV Med 2009;10.(Suppl. 1).

8. Nadjm B, Amos B, Mtove G, Ostermann J, Chonya S, Wangai H. WHO guidelines for antimicrobial treatment in children admitted to hospital in an area of intense Plasmodium falciparum transmission: prospective study. BMJ 2010;340:c1350.

9. Mayhood MK, Afwamba IA, Odhiambo CO, Ndanu E, Thielman NM, Morrissey AB. Validation, performance under field conditions, and cost-effectiveness of Capillus HIV-1/HIV-2 and determine HIV-1/2 rapid human immunodeficiency virus antibody assays using sequential and parallel testing algorithms in Tanzania. $J$ Clin Microbiol 2008;46(December (12)):3946-51.

10. Crump JA, Scott LE, Msuya E, Morrissey AB, Kimaro EE, Shao JF. Evaluation of the Abbott m2000rt RealTime HIV-1 assay with manual sample preparation compared with the ROCHE COBAS AmpliPrep/AMPLICOR HIV-1 MONITOR v1.5 using specimens from East Africa. J Virol Methods 2009;162(December (1-2)):218-22.
11. Scott LE, Crump JA, Msuya E, Morrissey AB, Venter WF, Stevens WS. Abbott RealTime HIV-1 m2000rt viral load testing: manual extraction versus the automated m2000sp extraction. J Virol Methods 2011;172: 78-80.

12. World Health Organization. Management of the child with a serious infection or severe malnutrition. In: Organization WH, editor. Guidelines for care at the first-referral level in developing countries. Geneva: World Health Organization; 2000., http://whqlibdoc.who.int/hq/2000/WHO_FCH_CAH_00.1.pdf.

13. World Health Organization. Policy requirements for HIV counseling and testing of infants and young children in health facilities. Geneva: WHO; 2010.

14. UNAIDS. AIDS epidemic update 2009. Geneva: WHO; 2009.

15. Udeh B, Udeh C, Graves N. Perinatal HIV transmission and the cost-effectiveness of screening at 14 weeks gestation, at the onset of labour and the rapid testing of infants. BMC Infect Dis 2008;8:174.

16. Ferreira Junior OC, Ferreira C, Riedel M, Widolin MR, Barbosa-Junior A. Evaluation of rapid tests for anti-HIV detection in Brazil. AIDS 2005;19(October (Suppl. 4)):S70-5.

17. Louie B, Wong E, Klausner JD, Liska S, Hecht F, Dowling T. Assessment of rapid tests for detection of human immunodeficiency virus-specific antibodies in recently infected individuals. J Clin Microbiol 2008;46(April (4)):1494-7.

18. Samdal HH, Gutigard BG, Labay D, Wiik SI, Skaug K, Skar AG. Comparison of the sensitivity of four rapid assays for the detection of antibodies to HIV-1/HIV-2 during seroconversion. Clin Diagn Virol 1996;7(October (1)):55-61.

19. Sherman GG, Driver GA, Coovadia AH. Evaluation of seven rapid HIV tests to detect HIV-exposure and seroreversion during infancy. J Clin Virol 2008;43(November (3)):313-6.

20. Claassen M, van Zyl GU, Korsman SN, Smit L, Cotton MF, Preiser W. Pitfalls with rapid HIV antibody testing in HIV-infected children in the Western Cape. S Afr J Clin Virol 2006;37(September (1)):68-71

21. National AIDS Control Programme (NACP). National Guidelines for the Management of HIV and AIDS. 3rd ed. Dar es Salaam: Government of Tanzania; November 2009.

22. Daar ES, Moudgil T, Meyer RD, Ho DD. Transient high levels of viremia in patients with primary human immunodeficiency virus type 1 infection. $N$ Engl J Med 1991;324(April (14)):961-4.

23. Schacker T, Collier AC, Hughes J, Shea T, Corey L. Clinical and epidemiologic features of primary HIV infection. Ann Intern Med 1996;125(August (4)): 257-64.

24. Krogstad P, Uittenbogaart CH, Dickover R, Bryson YJ, Plaeger S, Garfinkel A, et al infection of infants: the effects of somatic growth on lymphocyte and virus dynamics. Clin Immunol 1999;92(July (1)):25-33.

25. Dickover RE, Dillon M, Leung KM, Krogstad P, Plaeger S, Kwok S. Early prognostic indicators in primary perinatal human immunodeficiency virus type 1 infection: importance of viral RNA and the timing of transmission on long-term outcome. J Infect Dis 1998;178(August (2)):375-87.

26. Shearer WT, Quinn TC, LaRussa P, Lew JF, Mofenson L, Almy S. Viral load and disease progression in infants infected with human immunodeficiency virus type 1. Women and Infants Transmission Study Group. N Engl J Med 1997;336(May (19)):1337-42.

27. Read JS. Diagnosis of HIV-1 infection in children younger than 18 months in the United States. Pediatrics 2007;120(December (6)):e1547-62.

28. Karlsson MC, Wernersson S, Diaz de Stahl T, Gustavsson S, Heyman B. Efficient IgG-mediated suppression of primary antibody responses in Fcgamma receptordeficient mice. Proc Natl Acad Sci USA 1999;96(March (5)):2244-9. 